\title{
The Effect of Soil Types on the Growth Rate of Yam Seedlings Inferred from 2-D Electrical Resistivity Tomography
}

\author{
C.N. Ehirim and K.T. Obike \\ Geophysics research Group, department of Physics, University of Port Harcourt, P.0.Box 122, Choba, Port \\ Harcourt, Nigeria
}

\begin{abstract}
The impact of soil types and characteristics on the growth rateofyam seedlings has been presented. Yam seedlings were planted in two columns consisting of six different soil types and soil electrical resistivity variations due to variabilities in soil properties were measured to monitor growth rates in the different soil types for a period of 8 weeks using $2 D$ electrical resistivity tomography (ERT). Result shows high rate of growth for organic rich and well-structured soils than organic deficient and clayish soils. This is attributed to structure, moisture content and nutrient supply of the soil type to crop growth.2D resistivity inverse sections reveal that column 1 exhibit higher resistivity anomalies than column 2 in the study, which is attributed to varying waterholding capacity of the different soil types in each column. Comparison of the growth rate of the yam seedlings and $2 D$ inverse sections revealed that areas with high growth rates correspond to zones of relatively high values of electricalresistivity and low values of resistivity for areas of diminished crop growth. These results reveal that crop growth and yield could be predicted on the basis of electrical resistivity study and therefore, electrical resistivity technique can be adopted in precision farming for soil management and improved crop yield in the study area.
\end{abstract}

Keywords: Yam seedlings, growth rate, water- holding capacity, electrical resistivity, $2 D$ ERT

\section{Introduction}

The population and economic growth of any region is strongly dependent on the quality and productivity of the soil for its agricultural food production and other resources. According to UNDP (2006), food accounts for some $89 \%$ of needs by the average human being and a significant measure of healthy living. Quality soil is an essential requirement for plant growth and improved crop yield. However, the quality of soil has continuously been degraded by natural and anthropogenic agents resulting in nutrient depletion, poor soil structure and increasing decline in crop yields (Babalola and Zagal, 2000).

The impact caused on soil by these agents of degradation is significant, resulting in spatial and temporal variabilities in soil properties (structure, texture, moisture content, salinity, organic matter and bulk density). These variabilities in soil properties affect soil electrical properties, which can be monitored with the geoelectricalmethod. The electrical resistivity method has seen potentially encouraging applications in precision agriculture since soil properties can be correlated with soil electrical properties particularly, electrical resistivity in space and time to predict soil fertility and crop growth (Banton et al., 1997, Johnson et al., 2001)

Several authors (Tabbagh et al., 2000, Corwin and Lesch 2003, Anatja et al., 2005, Larisa and Anatoly, 2007 and Robert et al., 2009) have studied the application of electrical resistivity method in precision agriculture for soil management and improved yield of crop plants. The authors established that electrical resistivity of soils depend on their physical and chemical properties and therefore, can be used to distinguish fertile from poor quality soils in order to obtain optimum and quick growthof crop pants under field conditions.

The experimental farm is located in Uzuakoli, Abia State (Fig. 1.0). Uzuakoli is situated in the rainforest belt of south eastern Nigeria and receives annual rainfall of $1200 \mathrm{~mm}$, its peak being in the month of June. Temperature ranges from $23^{\circ} \mathrm{C}$ to $32{ }^{\circ} \mathrm{C}$ all through the year with the lowest temperatures recorded in the dry season (Okonkwo and Mbajiorgu, 2010). The topography is generally gently undulating and relatively flat in some areas especially in the experimental farm. Agriculture has remained the main stay of the economy and primary occupation of the people. The major crops grown in the area are maize, yam and cassava produced under subsistence farming. 


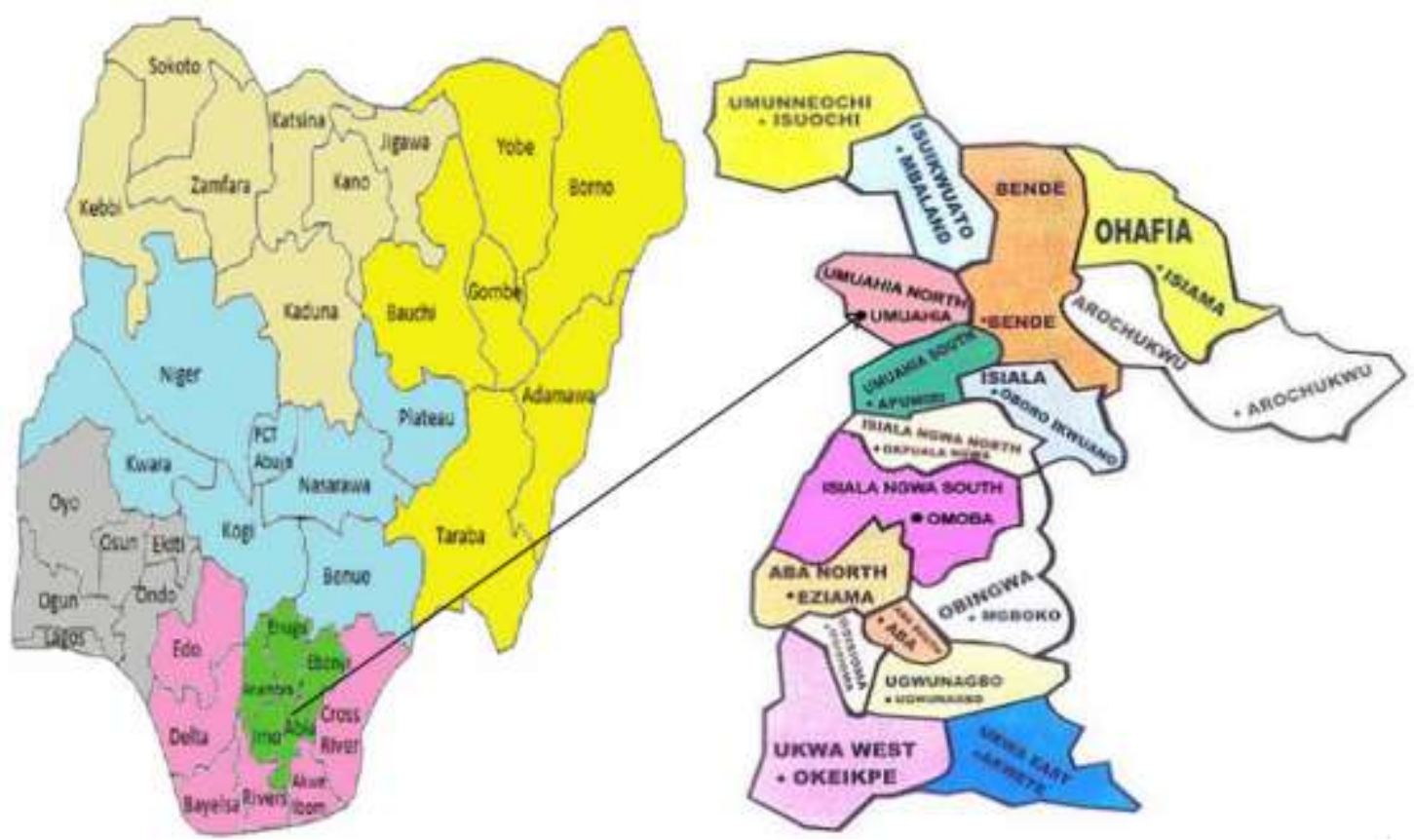

Fig 1.0: Location Map of the study area

Yam is a tropical crop grown in the genius Discorea. The most important staple specie of yam is Discorearotundat (white guinea yam) grown in the study area. Yam crops are heavy feeders and require productive soils such as loose textured sandy -loamy soil rich in organic matter and sufficient moisture for healthy growth. However, the sandy-loamy soil widespread in the area are loose textured but vary spatially in organic matter and moisture contents, thereby making yam production a function of location and space in the study area. Therefore, adequate application of the electrical resistivity method could be used to optimize soil fertility enrichment through the use of fertilizers and guide the cultivation of yam seedlings in productive and fertile soils for improved crop yield.

The aim of this study therefore, is to monitor soilelectrical resistivity due to different soil types on the growth rate of yam seedlings. This was achieved by planting yam seedling in different soil types and monitoring soil electrical resistivity variations due to variabilities in soil properties on the growth rate of yam seedlings using 2D electrical resistivity tomography.

\section{Methodology}

A $5 \mathrm{~m}$ by $10 \mathrm{~m}$ experimental farm was cleared of shrubs, grasses, and trees in order to expose the bare virgin soil (Fig. 2.0). The farm was divided into two columns $\mathrm{C} 1$ and $\mathrm{C} 2$ and four holes of $0.12 \mathrm{~m}$ diameter with inter- hole spacing of $0.75 \mathrm{~m}$ and hole depths of $0.3 \mathrm{~m}$ were dug in each column, which is in the range of burial depths for yam seedlings in the area. Column 1 hosted holes 1 to 4 while holes 5 to 8 are in column 2. Yam seedlings were planted in holes 1 to 6 consisting of different soil types under the same physiographic condition, while holes 7 and 8 are controls. The different soil types in each hole are shown in Table 1.

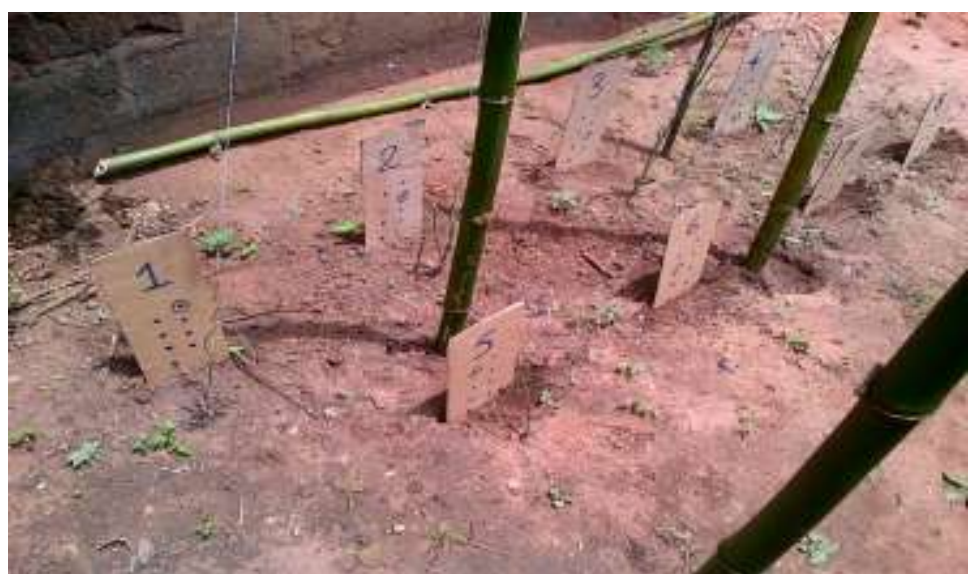

Fig. 2.0: Yam seedlings in different soil types in the experimental farm 
The Effect of Soil Types on the Growth Rate of Yam Seedlings Inferred from 2-D Electrical ..

Table1: Burial depths and soil types in each hole of thefarm

\begin{tabular}{|c|c|c|}
\hline Hole No. & Hole Depth & Soil Types \\
\hline 1 & 0.3 & Loamy-Sandy Soil + Fertilizer \\
2 & 0.3 & Loamy-Sandy Soil + Laterite \\
3 & 0.3 & Loamy-Sandy Soil + Organic Matter \\
4 & 0.3 & Loamy-Sandy Soil (Compacted) \\
5 & 0.3 & Loamy-Sandy Soil (Uncompacted) \\
6 & 0.3 & Lateritic clayish soil \\
7 & 0.3 & Lateritic clayish soil \\
8 & 0.3 & Sandy-Loamy Soil \\
\hline
\end{tabular}

The growth of the yam seedlings was monitored over a period of 8weeks between July and September, 2016, and plant heights and girths were measured weekly to determine growth rates in each soil type in the farm (Fig. 3.0). The growth rates (GR) were calculated using equation 1 given by,

$$
\mathrm{GR}=\mathrm{dH} / \mathrm{dt} 1
$$

where GR is the growth rate, $\mathrm{dH}$ is the change in height and $\mathrm{dt}$ is the change in time (week)

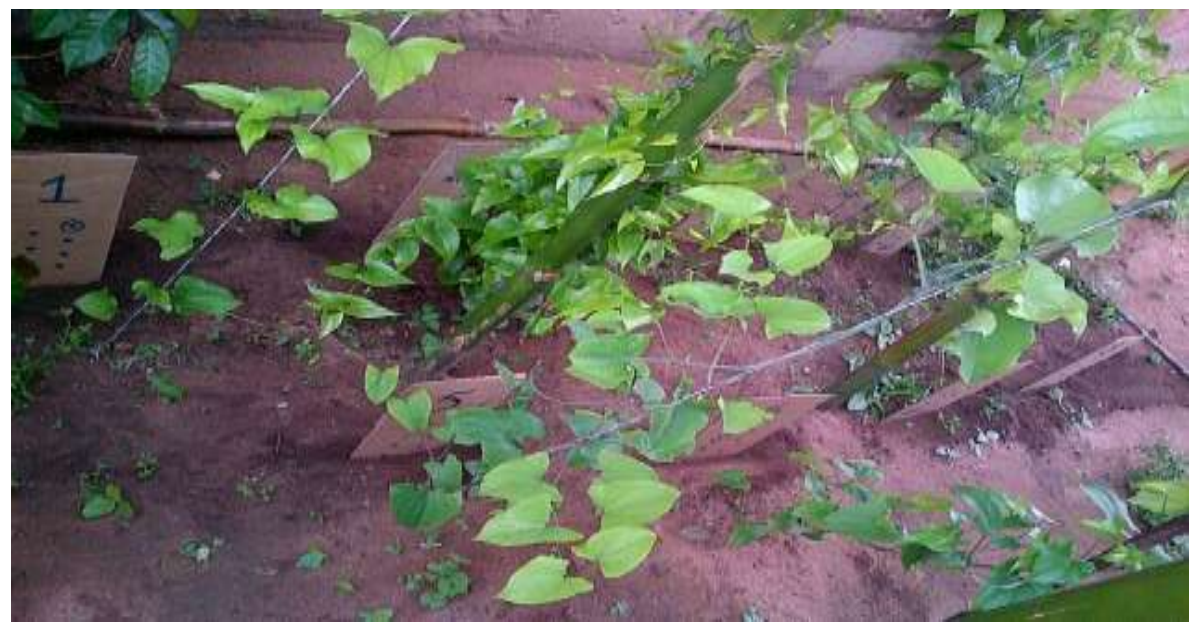

Fig. 3.0: Yam crops in eight weeks of growth in the different soil types

2D resistivity survey was carried out using Earth resistivity meter with alpha-wenner electrode configuration along a $10 \mathrm{~m}$ profile line for ' $\mathrm{a}$ ' spacing of 0.3 to $3.0 \mathrm{~m}$ weekly in each column for a period of 8 weeks. The apparent resistivity of the earth is calculated using equation 2 given by;

$$
\rho_{\mathrm{a}}=2 \pi \mathrm{aR}
$$

where $\mathrm{a}$ is the inter electrode spacing and $\mathrm{R}$ is the resistance of the ground

The ERT data were subjected to a 2D inversion process using RES2DINV (Loke and Barker, 1996), to determine the true electrical resistivity distribution of the soil forsubsequent analysis.

\section{Presentation of Results}

The result of growth analysis of yam seedlings in different soil types and 2D resistivity profiling is presented. Result shows different rates of growth of yam seedlings and the spatial variability in the electrical resistivity distributionunder different soil types in both columns of the experimental farm during the monitoring period of 8 weeks.

The measured heights of the yam seedlings vary from $200 \mathrm{~cm}$ to $609 \mathrm{~cm}$. The highest growth was observed in hole 3 (crop marker 3 ) and the least growth in hole 6 (crop marker 6) for loamy-sandy soil rich in organic matter and lateritic clayish soil, respectively, while the other soil types show intermediate growths (Fig.4.0). The calculated rate of growth varies between $28 \mathrm{~cm}$ to $87 \mathrm{~cm}$. Growth rates vary in the same pattern as the measured height of the yam seedlings. The growth rate was highest for yam seedlings in hole 3 column 1 and least in hole 6 column 2 (Fig.5.0), while yam seedlings planted in sandy-loamy soil with admixture of fertilizer (crop marker 1), 


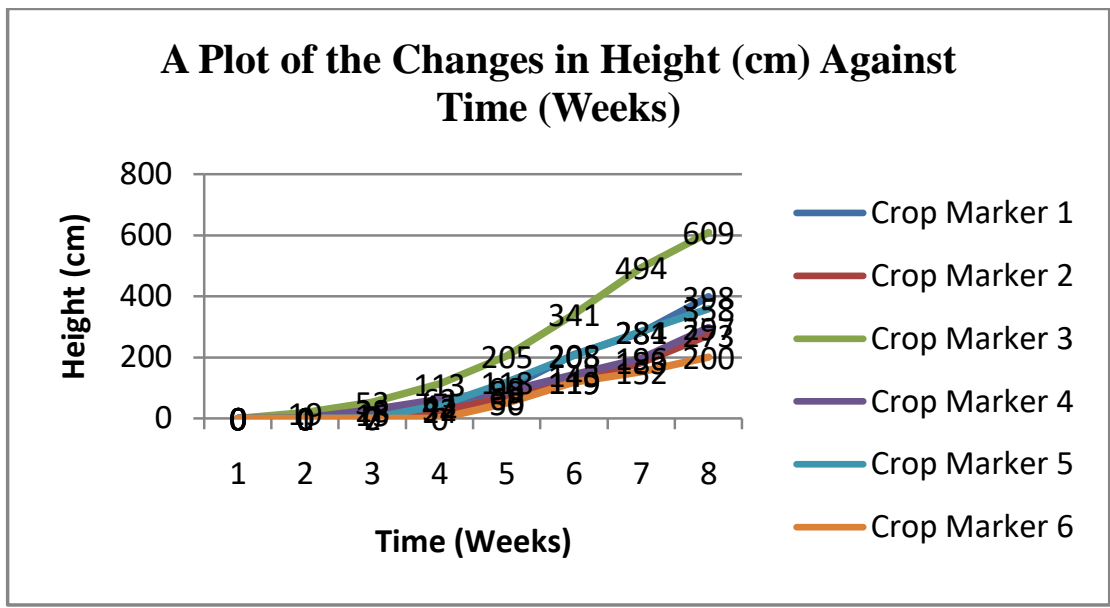

Fig 4.0: Changes in height of yam seedlings against time (weeks)

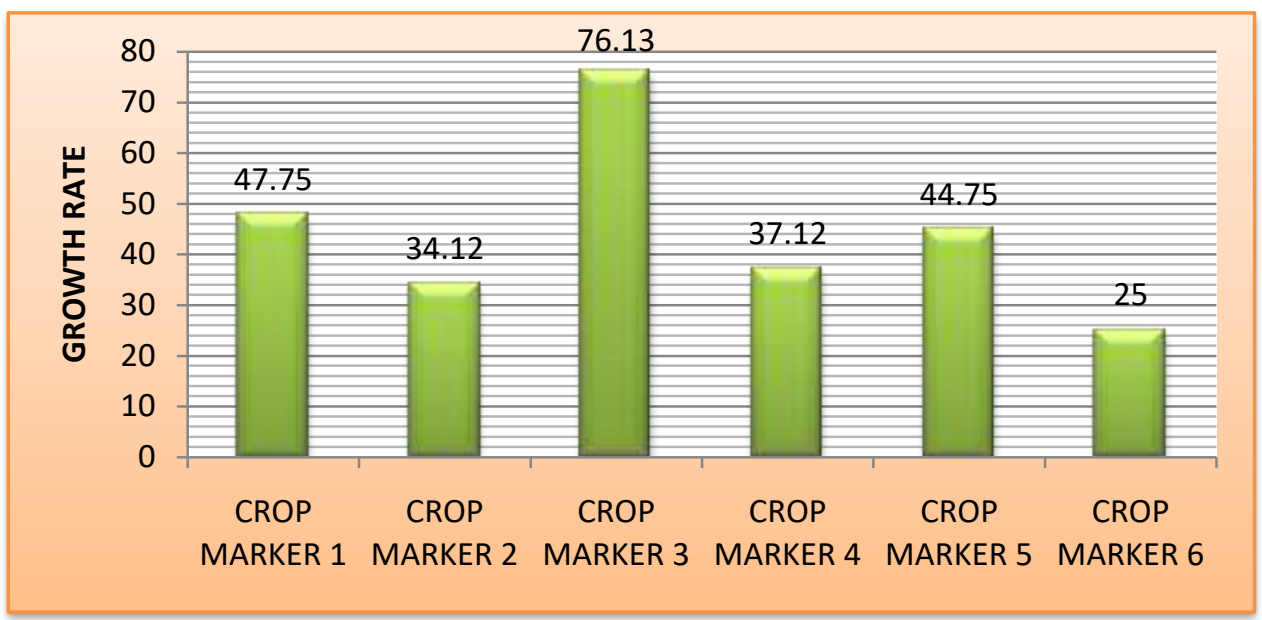

Fig 5.0: Plotof growth rate against crop markers

sandy-loamy soil (crop marker 4 and 5) and sandy-loamy mixed with lateritic soil (crop marker2), show intermediate growths, respectively. These observations reveal that soil type and characteristics affects growth rate of yam seedlings in the farm under the same physiographic condition.

2D apparent resistivity data were inverted into true resistivity distribution of the subsoil using RES2DINV (Loke and Barker, 1996). Typical 2D inverse sections for column 1 and 2 in the eight week of study are shown in Figs. 6a and b. The sections show lateral and vertical variabilities in subsoil electrical resistivity distributions. The resistivity varies between 122 to $254 \Omega \mathrm{m}$ and 151 to $194 \Omega \mathrm{m}$ within a subsoil thickness of $0.6 \mathrm{~m}$ for column 1 and 2, respectively, which is well below the root zones of the yam seedlings in the farm. Result shows that column 1 has higher resistivity distribution than column 2 in the farm related to the physical characteristics of the different soil types.

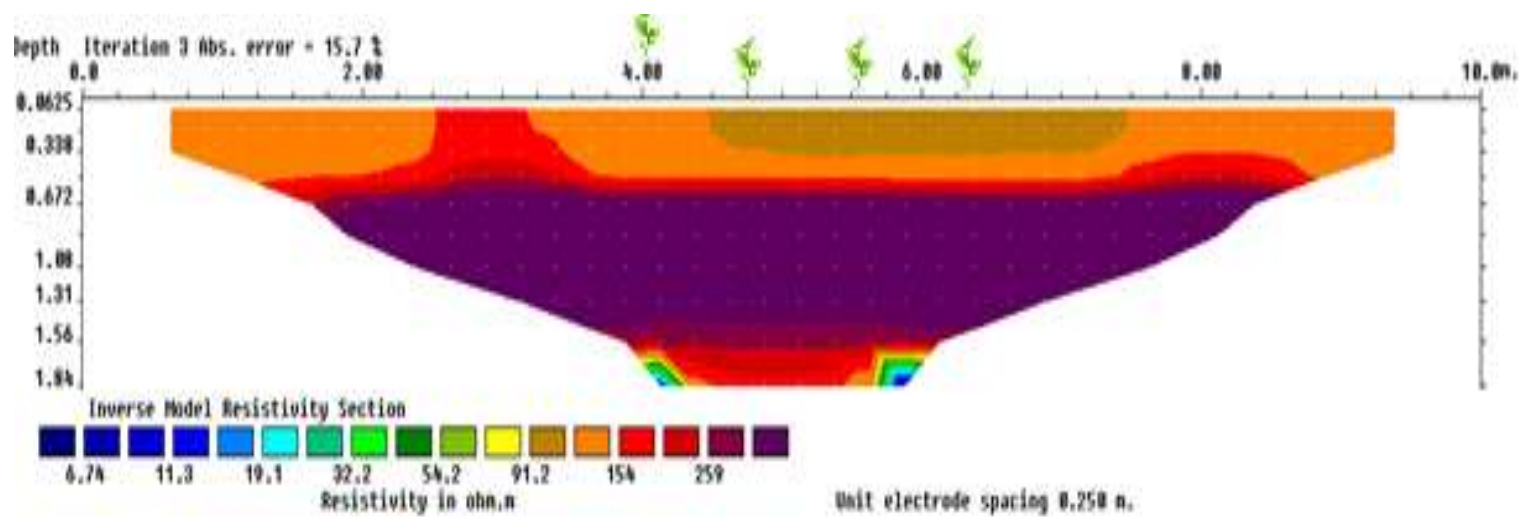

Fig.6a: Resistivityinverse section along column 1 for Week 8 


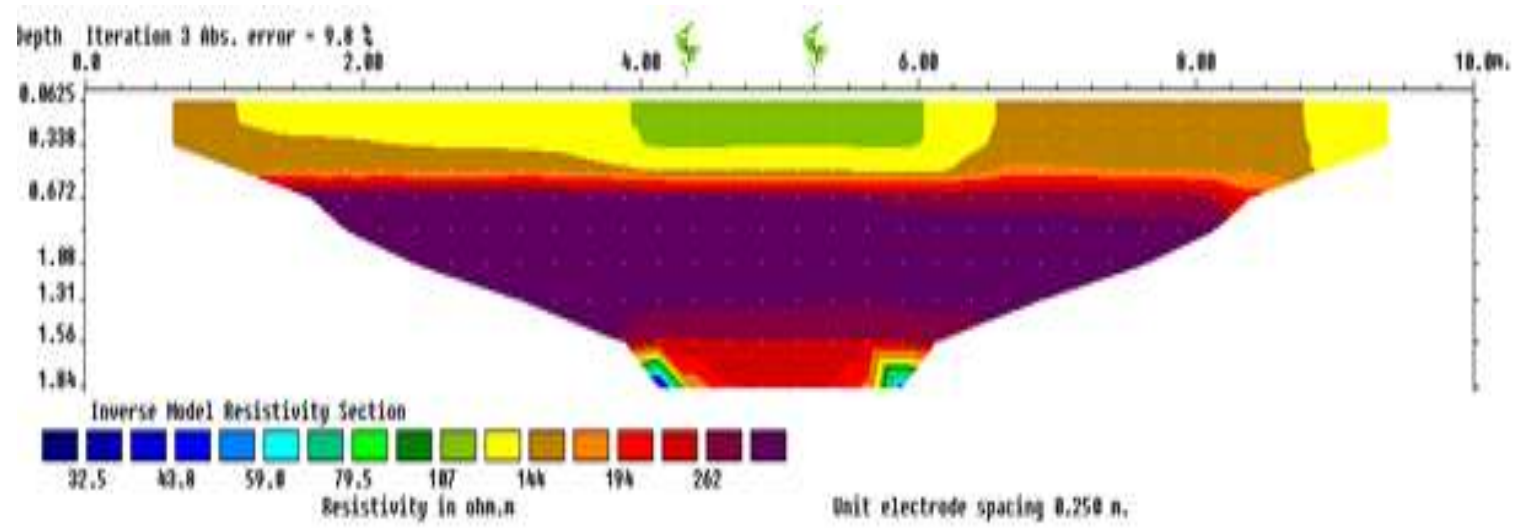

Fig. 6b: Resistivity inverse section along column 2 for Week 8

The 2D inverseresistivity sectionsrevealed significant correlation of electrical resistivities with the growth rate of yam seedlings. Result shows that the locations of fast growing seedlings correspond to zones of high resistivities and low values of resistivities for locations of diminished crop growth. High resistivity zones are due to soils of moderate moisture for plant growth while low resistivity zones are correlated with wet soils (Anatja et al., 2005), which is inadequate for crop growth. This significant correlation in growths (rate of growth) and electrical resistivity is linked to thedifferencein characteristics of the soil types in the farm.

\section{Discussion of Results}

Soil electrical resistivity due to different soil types on the growth rate of yam seedlings were measured and monitored using 2D resistivity method over a period of 8 weeks. The rate of growth correlates with soil characteristics such as structure, texture, organic matter and water content of the particular soil. It is highest in organic rich and well-structured soils than organic deficient and clayish soils.

High growth rate of yam seedlings were observed in hole 3 (crop marker 3) consisting of loamy-sandy soil rich in organic matter than the other soil types in the study. Result shows that addition of inorganic matter (fertilizer)into loamy-sandy soil improved growth rate of yam seedlings in hole 1(crop marker 1), but not as comparable as in the organic rich loamy-sandy soil in hole 3. Marker holes 2, 4, 5 and 6 containing soils deficient in organic matter exhibit varying rates ofgrowth. This is high in loamy-sandy soil (crop marker 4 and 5) than loamy-sandy soil mixed with lateritic soil (crop marker 2) and least in lateritic clayish soil (crop marker 6). This variability in growth rates is attributed to differences in structure, nutrients and water-holding capacity of the different soil types. The effects due to structure and nutrient supply on the growth rate of yam seedlings are high for organic, inorganic and loamy-sandy soils, respectively, than the lateritic and clayish soils. However, the effect of water-holding capacity is high for lateritic clayish soil than the other soil types, which retards growth of yam seedlings. This is because yam growths are enhanced under moderate soil moisture, sufficient nutrient supply and well-structured soil (Aighewi et al., 2015). Result also show low growth rate of yam seedlings in compacted loamy-sandy soil (crop marker 4) compared to the uncompacted loamy-sandy soil (crop marker 5). This is attributed to reduced pore volume due compaction resulting to decreased drainage, aeration and water-holding capacity of the soil which hampers crop growth.

The 2D ERT inverse sections in each column for the 8 week of growth show spatial variabilities of electrical resistivity caused by differences of soil characteristics. Result show that column 1 inverse section exhibits higher resistivity anomalies than column 2 in the study. These differences in resistivity anomalies are caused by the presence of soils with varying water-holding capacities. Electrical resistivity depends on the concentration and mobility of ions in the fluid filling the pore spaces of the rock. It is a function of saturation and quality of the saturating fluid and which varies inversely with soil water content (Scollar, 1977, Auerswald et al., 2000, Anatja et al., 2005).

The presence in column 1 of low water-holding capacity soils will significantly decrease the mobility of ions and increase electrical resistivity, while in column 2, the presence of high water-holding capacity soils in hole 6 and 7 at surface points 5.25 and $6.0 \mathrm{~m}$, respectively will increase the mobility of the ions and therefore decrease resistivity. The presence in hole 8 of natural loamy-sandy soil of low water-holding capacity increases resistivity. However, a low resistivity anomaly is associated with hole 5 (crop marker 5) in column 2 of loamysandy soil at $4.5 \mathrm{~m}$ surface point with low water-holding capacity. This low resistivity anomaly is attributed to the effect of high water-holding capacity soils in holes 6 and 7, respectively, in the neighbourhood of hole 5 which enhances saturation and reduce resistivity.

The result of 2D ERT, show a strong consistency between electrical resistivity and growth rates of yam seedlings in the different soil types. Comparison of the results revealed that areas with high growth rates 
correspond to zones of relatively high values of electrical resistivity and low values of resistivity for areas of diminished crop growth. This is consistent with the result of Banton et al., (1997), Corwin and Lesch (2003), Larisa and Anatoly (2007). Finally, the result of the present study has revealed that growth and crop yield could be predicted on the basis of electrical resistivity study and therefore, electrical resistivity technique can be adopted in precision farming for soil management and improved crop yield in the study area.

\section{Conclusion}

The present study has demonstrated the link between soil characteristics and electrical resistivity to the growth rate of yam seedlings in different soil types. High growth rates were observed in organic rich and wellstructured soils than organic deficient and clayish soils. This is attributed to structure, moisture content and nutrient supply of the soil type to crop growth.

The result of the 2D resistivity inversesections reveal that column 1 exhibit higher resistivity anomalies than column 2 in the study. This resistivity variation is caused by varying water-holding capacities of the different soil types. The presence in column 1 of low water-holding capacity soils significantly decreased the mobility of ions resulting in high electrical resistivity, while in column 2 the presence of high water-holding capacity soils increased the mobility of the ions and therefore, decrease electrical resistivity.

Comparison of the growth rate of the yam seedlings and 2D inverse sections revealed that areas with high growth rates correspond to zones of relatively high values of electrical resistivity and low values of resistivity for areas of diminished crop growth. These results reveal that crop growth and yield could be predicted on the basis of electrical resistivity study and therefore, electrical resistivity technique can be adopted in precision farming for soil management and improved crop yield in the study area.

\section{References}

[1]. Aighewi, B. A., Asiedu, A., Maroya, N., and Balogun, M. (2015): Improved propagation methods to raise the productivity of yam (DioscorearotundataPoir) Food Sec. 7, 823-834

[2]. Anatja, S., Isabelle, C., Alain, T., Ary, B., and Guy, R. (2005): Electrical resistivity survey in soil science: Soil and Tillage Research. Elsevier, 83, 173-193.

[3]. Auerswald, K., Simon, S. and Stanjek, H. (2000): Influence of soil properties on electrical conductivity under humid water regimes. Soil Sci pp

[4]. Babalola, O. and Zagal, E. (2000): Assessment of soil fertility degradation of Nigeria soils. A report submitted to the World Bank Assisted Project on Assessment of soil degradation in Nigeria. Federal Department of Land Resources Abuja, 73.

[5]. Banton, O., Seguin, M.K. and Cimon, M. A. (1997): Mapping field-scale physical properties of soil with electrical resistivity. Soil Sci. Soc. Am. J. 61, 1010-1017.

[6]. Corwin, D. L. and Lesch, S.M. (2003): Application of soil electrical conductivity to precision agriculture: theory, principle, and guidelines. Agron. J. 95, 455-471.

[7]. Larisa, G. and Anatoly, I. P. (2007): Electrical geophysical methods in agriculture. Proceedings of the $4^{\text {th }}$ International Symposium on Intelligent Information Technology in Agriculture (ISIITA) October 26-29, 2007, Beijing, china pg. 457-471.

[8]. Johnson, C.K., Doran, J. W., Duke, H. R., Wienhold, B. J., Eskridge, K. M. and Shanahan, J. F. (2001): Field-scale electrical conductivity mapping for delineating soil condition. Soil Sci Soc. Am. J. 235-234.

[9]. Loke, M. H. and Barker, R. D. (1996): Rapid least-square inversion of apparent resistivity pseudo sections using a quasi-Newton method. Geophys. Prospec. 44, 131-152.

[10]. Okonkwo, G.I. and Mbajiorgu, C.C. (2010): Rainfall intensity-duration-frequency analysis for South-eastern Nigeria. AgricEngInt: CIGR Journal, 12, 22-30

[11]. Robert, B. G., Mark, A., David, H., Wade, T. (2009): Precision farming tools: Soil electrical conductivity. Virginia cooperative extension publication $442-508$

[12]. Tabbagh, A., Dabas, M., Hesse, A.., Panissod, C. (2000): Soil resistivity: a non-invasive tool to map soil structure horizonation. Geoderma, 97, 393-404.

[13]. United Nations Development Program (2006): Niger delta human development report, 19 